\title{
"Videolarda Gerçek Hayattaki Gibi Değilim, Rol Yapmaktayım" : TikTok Kullanıcılarının Benlik Performansları Üzerine Bir inceleme ${ }^{1}$
}

\section{"I'm Not Like Real Life in Videos, I'm Pretending": A Review of The Self Presentations of TikTok Users}

\author{
Dr. Öğr. Ü. Derya GÜL ÜNLÜ2 \\ İstanbul Üniversitesi Illetişim Fakültesi \\ Halkla İlişkiler ve Tanıtım Bölümü \\ *ORCID: 0000-0003-3936-7988 \\ Dr. Oğuz KUŞ \\ İstanbul Üniversitesi İletişim Fakültesi \\ Halkla İlişkiler ve Tanıtım Bölümü \\ *ORCID: 0000-0002-2593-4980 \\ Doç. Dr. Oğuz GÖKSU ${ }^{4}$ \\ Gaziantep Üniversitesi İletişim Fakültesi \\ Halkla İlişkiler ve Tanıtım Bölümü \\ *ORCID: 0000-0002-7923-8761
}

\section{öz}

Dijital iletişim ortamlarının kullanımının yaygınlaşması, bireylerin benlik performanslarını sergilemelerine olanak sağlayan sahneleri de çeşitlendirmiştir. Günümüzde bireyler, kişisel hesapları üzerinden kendilerine dair hedefledikleri benlik sunumlarını takipçilerine/arkadaşlarına sergileyebilmekte ve böylelikle dijital benliklerini inşa edebilmektedirler. Bu süreçte özellikle video paylaşım platformlarının, hem kullanıcılarını performanslarını sergileyebilecekleri izleyicilerle buluşturması hem de birey ile izleyici arasındaki etkileşimi sağlayacak teknik bir altyapı sunması bakımından ön plana çıktığını söylemek mümkündür. Söz konusu video paylaşım platformlarından biri olan TikTok ise, bireyin benlik sunumunu gerçekleştirebilmesi için videolarını düzenleyerek, ilgi çekici kılabileceği ve diğer kullanıcılarla etkileşime girebileceği güçlü bir teknik altyapı sağlaması dolayısıyla benzerlerinden ayrılmaktadır. Bu odak noktasından hareketle gerçekleştirilen çalışma, TikTok kullanıcılarının, paylaştıkları video içerikleri aracılı̆̆ıla sergiledikleri benlik performanslarını analiz etmeyi amaçlamakta ve TikTok kullanıcılarının video içeriği oluştururken sahne arkasında nasıl bir hazırlık yaptıkları, video paylaşımlarını hangi kriterleri gözeterek gerçekleştirdikleri ve hedefledikleri dijital benlik sunumuna uygun olarak hangi video içeriklerini paylaşmayı/paylaşmamayı öncelikli olarak tercih ettikleri sorularına yanıt aramaktadır. Ayrıca kullanıcıların içerik üretim motivasyonları ve içerik üretimi sonucundaki beklentilerinin keşfedilmesi de çalışma hedefleri arasında yer almaktadır. Bu kapsamda, yarı yapılandırılmış yüz yüze görüşme tekniğine dayanan betimsel bir alan araştırması gerçekleştirilmiştir. Çalıșma sonucunda ise, katılımcıların kişisel TikTok hesapları üzerinden yayınladıkları video içeriklerini, hedefledikleri dijital benlik sunumları doğrultusunda yapılandırdıkları ve videolarını yayınladıktan sonra takipçilerinden aldıkları etkileşim oranına bağlı olarak performanslarını şekillendirdikleri bulgulanmıştır.

Anahtar Kelimeler: Benlik sunumu, dijital benlik sunumu, TikTok.

\footnotetext{
${ }^{1}$ Makalenin Türü: Araştıma Makalesi

2 derya.gul@istanbul.edu.tr

3 oguz.kus@istanbul.edu.tr

${ }^{4}$ oguz.goksu@iletisim.gov.tr
} 
Extended Abstract: The proliferation of digital communication environments has also diversified scenes that allow individuals to perform self-performance. Nowadays, people can show their target-self presentations to their followers/friends through their personal accounts and thus build their digital selves. In this process, it is possible to say that video sharing platforms in particular come to the fore in terms of bringing their users together with viewers who can perform and providing a technical infrastructure to enable interaction between the individual and the viewer. TikTok, one of the video sharing platforms in question, is separated from its counterparts by editing their videos so that the individual can perform the self-presentation, providing a strong technical infrastructure that can make them interesting and interact with other users. Because TikTok provides users with opportunities such as editing videos, making them more engaging (sound effects, filters, tags) and interacting with other users (using original hashtags, challenges, and algorithms) and thus enabling the digital self-presentation to be performed effectively. It is also seen that TikTok's distinctive structure differentiates the user's digital self-performance experience. TikTok users prefer functions such as the hashtag, which has a common use in most social networks, because it offers different functions specific to TikTok. In addition, the fact that the content production and consumption process among users is rising on a collaborative interactive production basis such as duets and video responses makes TikTok an essential platform to research, which brings a new perspective to existing social media functions and understanding.

The study, which is based on this focus, aims to analyze the self-performance that TikTok users perform through the video content they share. In addition, the discovery of users' expectations as a result of content production motivations and content production is also among the working goals. In this context, a scriptary field survey based on a semi-structured face-to-face interview technique was carried out. In-depth interview design and implementation protocol put forward by DeMarris (2003) during the face-to-face interview process was used. In determining the participants who will take part in the field research, the method of sampling was used in accordance with the purpose. Participants included in the study accordingly. According to the categorization of Zea and Heekyoung (2019), participants have been selected from individuals who are included in the creative group, i.e. individuals who actively produce content and regularly track shared content with other users. Thus, it is aimed to select the participants included in the study from users who perform in front of the stage at TikTok and interact with their followers, compared to the user profiles in other categories.

As a result of the study, it was determined that these videos, which participants chose from the current and popular topics in TikTok, will not lead to a negative self-presentation of the video content they will share for themselves, as well as the content of the users, going through an editing process behind the scenes until they reach the stage of publication. Accordingly, users make several editing such as adjusting the camera angle, checking the background, memorizing lyrics and making various arrangements, such as trial shooting. Among the most important arrangements where it is thought to increase the quality of the content to be shared are the memorization of the lyrics and the practice shoot. Once the preparation process of the video is complete, users finalize the content that is ideal for self presentations through editing tools such as using effects, editing video color, sound and duration, and adding various stickers. In fact, they even get approval of the suitability of the content by sending the final version of the video to their immediate surroundings. The agreed content is shared in the evening hours, which is thought to be the time interval in which TikTok is most used. In addition, users refrain from adding too much text in the video content they share because they think it is appropriate for TikTok's structure and will get more interaction and they also add hashtags or emoji, and short video captions.

When the thoughts of the participants about the content they bring to the stage by preparing behind the scenes are examined, it is seen that they take a different role depending on the concepts of their TikTok videos and they express that they are completely different from their offline selves because of these roles they undertake. Among these roles adopted, the appearances sympathetic and fun to the follower come to the forefront, and users are found to shape their video content in this direction. In addition, users are particularly avoiding sharing some content in order to showcase the self-presentations they want to take to the front of the stage. These content include content that users believe is personal information and not suitable for their own presentations. Furthermore, the likelihood that users will get more interactions does not affect their decision not to share content that they don't think fit sings. On the other hand, the interaction rate is the most important criterion that the user considers when choosing from content that he thinks is appropriate for his own self presentation.

Key Words: Self-presentation, digital self-presentation, TikTok.

\section{GiRiş}

Sosyal medya, bireye benlik sunumunu sergileyebileceği dijital sahneler sunmakta ve böylelikle birey, kendisi hakkında dikkat çekeceğini, beğenileceğini ya da takdir edileceğini düşündüğü içeriği düzenleyerek yayınlama imkanına sahip olmaktadır. Bireylerin sosyal medya ortamlarındaki benlik performanslarını ele alan çok sayıda 
çalışmanın, çoğunlukla, Facebook (Bryant \& Marmo, 2012; Medizadeh, 2010; Seidman, 2013; Vogel \& Rose, 2016; Zhao vd., 2008), Twitter (Lebel \& Danylchuk, 2012; Lebel \& Danylchuk, 2014), Instagram (GeurinEagleman \& Burch, 2016; Jackson \& Luchner, 2018; Smith \& Sanderson, 2015) ve YouTube (Chen, 2016) gibi popüler platformların kullanıcılarına dijital benliklerini inşa edebilmeleri için sunduğu uygun altyapıya ve bireyin bu altyapıdan yararlanarak, benlik performansını nasıl sergilediğine odaklandığı görülmektedir. Diğer yandan, sosyal medya ortamlarından biri olan video paylaşım platformlarının, kullanıcının dijital benlik performansını sergileme sürecinde üstlendiği rolünün de yeterince ele alınmadığını söylemek mümkündür. Oysaki video paylaşım platformları, kullanıcılarını performanslarını sergileyebilecekleri izleyicilerle buluşturması ve birey ile izleyici arasındaki etkileşimi sağlayacak teknik bir altyapı sunması bakımından önem taşıyan sosyal medya mecraları arasında yer almaktadır. Söz konusu video paylaşım platformları arasında ise, TikTok, hem Türkiye'de hem de küresel ölçekte önemli bir kullanıcı kitlesine ulaşmış olmasına rağmen, bu yeni mecrada benlik performanslarını ele alan bir çalışmanın bulunmaması dikkat çekmekte ve bu alanda gerçekleştirilecek bir araştırmaya ihtiyaç duyulmaktadır. Çünkü, Tiktok kullanıcılarına videoları düzenleme, daha ilgi çekici kılma (ses efektleri, filtreler, etiketler) ve diğer kullanıcılarla etkileşime girme (özgün hashtag kullanımı, challenge'lar, kullandığı algoritma) gibi olanaklar sağlayan ve böylelikle dijital benlik sunumunun efektif bir şekilde gerçekleştirilmesini mümkün kılan güçlü bir teknik altyapı sunmaktadır.

Şüphesiz, sosyal medya ortamlarında gerçekleştirilen benlik sunumu araştırmalarının göz önünde bulundurduğu değişkenler, TikTok'taki benlik performanslarını araştırmak ve anlamlandırmak noktasında önemli bir yol haritası sağlamaktadır. Ancak, TikTok'un kendine özgü yapısının kullanıcının dijital benlik performansı deneyimini de farklılaştırdığı görülmektedir. TikTok kullanıcıları, sosyal ağların çoğunda ortak bir kullanıma sahip olan hashtag gibi fonksiyonları TikTok'a özgü farklı işlevler sunması nedeniyle tercih etmektedir. Ayrıca kullanıcılar arasındaki içerik üretim ve tüketim sürecinin, düet ve videolu cevaplar gibi işbirlikçi (Zea \& Heekyoung, 2019) bir etkileşimli üretim zemininde yükseliyor olması mevcut sosyal medya fonksiyonlarına ve anlayışına yeni bir bakış açısı getiren TikTok'u araştırılması elzem özgün bir platform haline getirmektedir.

Bu çerçevede gerçekleştirilen çalışma, dijital benlik sunumu konusundaki teorik zemini ve öncül araştırmaların bu konuyu farklı dijital platformlar bağlamında değerlendirerek ulaştığı sonuçları göz önünde bulundurarak, TikTok kullanıcılarının benlik performanslarını analiz etmeyi amaçlamaktadır. Ayrıca kullanıcıların içerik üretim motivasyonları ve içerik üretimi sonucundaki beklentilerinin keşfedilmesi de çalışma hedefleri arasında yer almaktadır. Bu amaç doğrultusunda, TikTok kullanıcılarının video içeriği oluştururken sahne arkasında nasıl bir hazırlık yaptıkları, video paylaşımlarını hangi kriterleri gözeterek gerçekleştirdikleri ve hedefledikleri dijital benlik sunumlarına uygun olarak hangi video içeriklerini paylaşmayı/paylaşmamayı tercih ettikleri sorularına yanıt aranmaktadır. Çalışma, yerel ve küresel ölçekte yeterli miktarda çalışılmamış bir platform üzerine yürütüldüğünden TikTok'ta farklı kullanıcı profilini yansıtan katılımcılar amaca yönelik örnekleme yöntemiyle seçilmiş ve 9 farklı kullanıcı ile yarı yapılandırılmış yüz yüze derinlemesine görüşmeler gerçekleştirilmiştir. Çalışma sonuçlarına erişebilmek için öncelikle sosyal ağlardaki benlik performansına değinilerek video paylaşım platformlarındaki benlik sunumu pratikleri ele alınmış ve söz konusu platformlar arasından TikTok'un kendine özgü yapısal özellikleri aktarılmıştır. Çalışmanın araştırma bölümünde ise, TikTok kullanıcılarıyla gerçekleştirilen yarı yapılandırılmış görüşmelerin detaylarına, görüşmelerden alıntılanan bölümlere ve bu görüşmelerin analizi sonucunda ulaşılan sonuçlara yer verilmiştir.

\section{Benlik Kavramı ve Sosyal Medyada Benlik Sunumu}

Benlik kavramı, "her bireyin kendi öz kişiliği ve sosyal dünyasındaki olaylar, nesneler hakkında sahip olduğu geniş bilgiyi içeren zihinsel temsil” (Kihlstorm \& Cantor, 1984: 13) olarak tanımlanmaktadır. Bu bakımdan, benlik kavramı, bireyin kendi hakkındaki temsillerinin bütününü ifade etmektedir. Bu açıdan benlik, kişinin kendisi, vasıfları ve özellikleri hakkında sahip olduğu genel fikir biçiminde tanımlanabilir, bir kişinin, kendisine ilişkin bilişsel temsillerini içeren algılarının bir özeti gibi düşünülebilir (Bilgin, 2016: 50). Benlik sunumu ise, temel olarak, bireyin sahne önü ve arkası performansları aracılığıyla gerçekleştirdiği ve kendisine dair bu iki performans alanını müzakere ederek, benlik performansını izleyicide hedeflediği etkiyi oluşturacak biçimde şekillendirdiği bir sürece karşılık gelmektedir (Goffman, 2016). Performans olarak nitelenen bu sunumlarla bireyler, kendilerine dair sahip olmayı istedikleri izlenimleri izleyicilerine yansıtmayı amaçlamakta (Jensen \& 
Gilly, 2003) ve izleyicileriyle kurdukları etkileşim aracılı̆ııla, kendi izlenimleri üzerinde bir anlaşmaya varmayı hedeflemektedirler. Dolayısıyla bir hedefe odaklı olan benlik sunumu (Leary \& Kowalski, 1990), bireyin kendine dair amaçları ile izleyicinin onun benliğine dair sahip olacağı izlenim arasında bir denge kurabilmesini ifade etmektedir (Bortree, 2005). Ayrıca bu denge kurabilme süreci, bireyin benlik sunumu stratejilerini içeren iki performans alanını sürekli müzakere etmesini, izleyiciyi, kendi amaçlarını ve bağlamı sürekli yorumlayarak devamlı kontrol etmeye çalışmasını da içermektedir.

Bununla birlikte, bireyin benlik sunumu süreci sadece çevrimdışı hayatıyla sınırlı değildir. Dijital iletişim araçlarının kullanımının yaygınlaşmasıyla birlikte, kullanıcılar dijital ortamın kendilerine sunduğu sahnelerde yer alabilme ve bu ortamda etkileşim halinde bulundukları kişilere dijital benliklerini sunabilme imkanını elde etmişlerdir. Bu çerçevede, özellikle bireyin kullanıcısı olduğu sosyal medya hesaplarının oldukça önemli bir işlev üstlendiğini ifade etmek olanaklıdır. Sosyal medya ortamındaki benlik sunum pratiklerini ele alan çalışmalar incelendiğinde (Davis, 2012; Hogan, 2010; Smith \& Sanderson, 2015; Vogel \& Rose, 2016; Yau \& Reich, 2018); bireyin benlik sunumu sürecinde izleyicisiyle fiziksel olarak bir arada bulunma zorunluluğunun ortadan kalktığı, izlenim yönetimini kamusallaştırabildiği, kendisini bir başkasının gözünden görebilme imkanı elde ettiği, çevrimdışı ortama nazaran öncesinde benlik sunumunu kurgulayabileceği daha fazla zamana sahip olabildiği, kendisine ilişkin paylaştığı içeriği istediği izleyici kitlesine sunabildiği ve beğenileceğini düşündüğü içeriği niyetli bir biçimde paylaşabildiği görülmektedir. Dolayısıyla, sosyal ağların bireye kendi alternatif benliğini ifade edebilmesi için benzersiz bir ortam sağladığını (Seidman, 2013: 402) ve kullanıcının bu sayede kendini yaratmanın mükemmel bir olanağına sahip olarak, istediği görsel ya da metinsel içeriği sanal benliğine yerleştirildiğini (Timisi, 2005: 97) söylemek mümkündür.

Bireyin dijital benliğini inşa ederken, çevrimdışı ortama kıyasla çok daha fazla kontrole sahip olduğu; kendi dijital benliğini oluşturan parçalar üzerine düşünebildiği, bu parçaları yeniden kurgulayabildiği, kişiselleştirebildiği ya da takipçilerinden/arkadaşlarından aldığı etkileşimler aracılığıyla performansını yeniden şekillendirebildiğini söylemek mümkündür (Caplan, 2005; Gibbs, Ellison \& Heino, 2006; Papacharissi, 2002; Rosenberg \& Egbert, 2011; Smith \& Sanderson, 2015; Van Der Heide vd., 2012). Ayrıca dijital ortamın, bireyin çevrimdışı ortamda izleyicileriyle yüz yüze etkileşim halindeyken kendi benliğine dair uygun olmadığını düşündüğü ya da arzulanmayan parçaları da, gizleyebilmesine ya da dönüştürebilmesine olanak sağladığı da vurgulanmaktadır (Kim \& Papacharissi, 2003).

Diğer yandan, sosyal medya kullanıcılarının paylaştığı içeriğin kim tarafından izlendiğinin/görüldüğünün tam olarak bilinmesinin olanaksızlığı (Litt, 2012) ve bireyin sosyal hayatta etkileşim halinde bulunduğu farklı sosyal grupların çevrimiçi ortamdaki bir aradalığı (Marwick \& boyd, 2011), izleyiciye sergilenen benlik performansı açısından da oldukça önem taşımaktadır. Çünkü aslında birey, etkileşim halinde bulunduğu farkı sosyal gruplardan oluşan, tam olarak bilemediği ve dolayısıyla hayal ettiği izleyiciye yönelik bir benlik performansı gerçekleştirmektedir. Bu bakımdan değerlendirildiğinde, bireyin kendisini tanımlayan bir profil sayfası oluşturarak sosyal ağlara katılımıyla başlayan bu süreçte, hayal ettiği izleyiciye hitaben kendi profilini düzenlediğini ve karşı tarafa aktardığını söylemek olanaklıdır. Sosyal ağların bireyin kimlik keşfi ve inşasına olanak tanıyan (Yau \& Reich, 2018: 196) bu özelliği ise, kullanıcının kişisel özellikleri ve yaşamına dair olumlu yönlerini ön plana çıkarabilmesi (Chou \& Edge, 2012; Zhao vd., 2008) için önemli bir alt yapı sunmaktadır. Hatta öyle ki, Yau ve Reich (2018) tarafından gerçekleştirilen araştırma sonuçları, gençlerin sosyal ağlarda paylaşım yapmadan önce akranlarının görüşüne başvurduğunu ve üzerinde fikir birliğine varılan en fazla beğenilme potansiyeline sahip içeriğin paylaşıldığını ortaya koymaktadır. Diğer yandan, birey hakkında gerçekleştirilen paylaşımların da bireyin benlik performansının bir parçasını oluşturduğunu eklemek gerekmektedir. Bireyin dijital benlik performansı, kendisinin paylaştığı ve onun hakkında paylaşılanların (gönderilere gelen yorumlar, beğeniler, etiketlendiği fotoğraf, video ya da mekanlar) bir bütünüdür.

\section{Video Paylaşım Ortamlarında Benlik Sunumu}

YouTube, Snapchat, Vine, TikTok gibi video paylaşım ortamları, kullanıcısına gerçekleştirdiği paylaşımın içeriğini, süresini belirleme olanağı sunarak, bireye kendisini dilediği gibi ifade edebilme özgürlüğü tanımaktadır. Söz konusu dijital ortamların kullanıcıya sunduğu bu avantajın ise, dijital benlik inşası ve sunumu için önemli bir 
altyapı sağladığını söylemek mümkündür. Paylaşılan bir videonun süresi, çekim açıları, kullanılan mekan, müzik, görsel, sözel ve yazılı içerik gibi çok sayıda faktörün bireyin hedeflediği dijital benlik sunumunun birer parçası olarak kullanılabileceği düşünüldüğünde, paylaşılan video içeriğinde tercih edilen her bir unsurun bireyin performansına katkı yapacak parçalara dönüştüğünü söylemek yanlış olmayacaktır. Bu bakımdan değerlendirildiğinde, video paylaşım ortamlarının bireye kendisiyle ilgili paylaştığı bilgi üzerinde yüksek kontrol imkanı sunduğu (Pace, 2008) ve böylelikle bireyin idealize ettiği benlik sunumunu gerçekleştirmesi için önemli bir altyapıya sahip olduğu görülmektedir. Kullanıcılara sunulan bu teknik altyapı, günümüzde bireylere yayınladıkları videoları aracılığıyla inşa ettikleri dijital benliklerini izleyicilerine kolay ve hızlı bir biçimde sunma imkanı tanımaktadır. Ancak video paylaşım platformlarında paylaşılacak bilgi üzerindeki kontrol sürecinin, görsel içeriğin düzenlemesine dayalı olduğu ve bu nedenle kullanıcıların dijital benlik performanslarını sergilemelerine olanak sağlayacak içeriğin niteliğine bağlı olarak kaygı düzeylerinde artış yaşayabileceklerini de eklemek gerekmektedir. Bu bağlamda, Fardouly ve arkadaşları (2019) tarafından, ergenlik öncesi yaş aralığında bulunan kullanııılara yönelik olarak gerçekleştirilen araştırma sonuçları; Youtube, Instagram ve Snapchat kullanııılarıın vücutlarının görünümüne yönelik daha fazla kaygı belirttiklerini ortaya koymaktadır. Araştırmacıların değinmiş olduğu noktadan hareketle, adı geçen platformların bütünüyle fotoğraf ve video gibi görsel içeriklerin paylaşımına odaklandığını göz önünde bulundurarak, video paylaşmaya olanak tanıyan sosyal medya platformu kullanıcılarının benlik sunumlarında önemli bir hazırlık süreci olabileceği, sahnenin arkası ve sahnenin önü arasında belirgin bir fark gerçekleşebileceği, hatta bunun kimi zaman olumsuzluklara neden olabileceği yorumunu yapmak mümkündür.

Buna ek olarak, söz konusu videolara yapılan yorumlar, beğeniler aracılığılla iki taraf arasında kurulan ilişki üzerinden izleyicinin izlediğiyle kurduğu parasosyal etkileşim (Chen, 2013; Chen, 2016; Kurtin vd., 2018; Rasmussen, 2018) de bireyin kendisi hakkında diğerlerinin sahip olmasını istediği dijital benliğini inşa edilmesi ve karşı tarafa sunabilmesi için önemli bir potansiyele sahiptir. Video içeriğini oluşturan ve izlenmek üzerine dolaşıma sokan birey, kendisini izleyen ve takip eden diğerleri tarafından beğenilmekte, özenilmekte ve takdir edilmektedir (Ko \& Wu, 2017; Rasmussen, 2018). Bu bağlamda, Youtube, TikTok gibi video paylaşım platformlarının video içerikleri aracılı̆̆ıyla parasosyal etkileşime katkı sağladığını ve sergileyen ile izleyen arasında var olan anlamları geliştirdiği görülmektedir (Kağıtçıbaşı, 2006: 218; Chen, 2013). Bu bakımdan ele alındığında, bireyin hedeflediği benlik sunumunu gerçekleştirebilmesinin kendisini izleyenlerin onunla ne derece parasosyal etkileşim kurabildiğiyle de yakından ilişkili olduğunu söylemek mümkündür. Video paylaşım platformlarında, içerik üreticisi ve kullanıcı arasında kurulan parasosyal etkileşim ise, beğenme, tekrar paylaşma gibi reaksiyon fonksiyonları aracılığıyla gerçekleştirilmektedir.

Parasosyal etkileşimin yanı sıra, video paylaşım platformlarının kullanıcısına sahne arkasında hedeflenen benlik performansını gerçekleştirebilmesi için önemli bir hazırlık imkanı sunduğu da görülmektedir. Ayrıca, görsel ve işitsel efektler, etiketler, video düzenleme araçları ve filtreler gibi teknik olanaklar da kullanıcıların yüksek bir teknik bilgiye sahip olmadan videolarını istedikleri izlenimi yaratmak üzere düzenlemelerine olanak tanımaktadır. Diğer yandan, Bortree'nin (2005) bireyler izleyicileriyle kurdukları etkileşimle birlikte, kendi izlenimleri üzerinde bir anlaşmaya varmayı hedeflemektedirler önermesi göz önünde bulundurulduğunda, video platformlarının hem bireyleri benlik sunumunu gerçekleştirecekleri izleyiciyle buluşturmak hem de birey ile izleyici arasındaki anlaşmayı sağlamak üzere teknik olanaklar yaratmak bakımından önem taşıdığını söylemek yanlış olmayacaktır. Ayrıca gün geçtikçe kullanıcı hakkında daha fazla bilgi sahibi olan algoritmaların belirli bir içeriği potansiyel olarak ona ilgi duyanlara gösterdiği düşünüldüğünde, içeriği gören kullanıcıların bu içeriği değerlendirebilmesi ve ona yorum yapabilmesinin hem benlik sunumunun gerektirdiği etkileşimin yaratılmasına hem de bu sunum üzerinde anlaşmaya varılmasına olanak tanıdığını da eklemek gerekmektedir.

\section{Bir Video Paylaşım Ortamı Olarak TikTok}

TikTok, ByteDance isimli teknoloji şirketi tarafından yaratılmış olan Çin merkezli bir video paylaşım platformudur. Çin'de Douyin, uluslararası bağlamda ise TikTok olarak bilinen uygulama Çin'de 300 milyondan fazla (Shao, Wang \& Hao, 2019) ve dünya çapında 800 milyon (Bump, 2019) aylık aktif kullanıcıya sahiptir. TikTok, kullanıcılarına videolarını görsel olarak daha çekici hale getirmek için özel efektler, animasyonlar, etiketler ve video düzenleme araçları sağlamaktadır. Buna ek olarak, platform, kullanıııların içerik tercihlerini 
baz alarak kişiselleştirilmiş içerikler önermektedir (Zhang, Wu \& Liu, 2019; Lu \& Lu, 2019). Uygulamayı Vine, Snapchat ve Musical.ly (TikTok'un yaratıcısı ByteDance tarafından 2017 yılında satın alınmıştır) uygulamalarının bir karışımı olarak betimlemek mümkündür (Salinas, 2018). TikTok, bir başka kullanıcı ile düet videosu yaratma (duet) veya bir başka kullanıcıya video ile yorum yapma (react) gibi yeni işbirlikçi ve kapsayıcı kullanıcı deneyimlerini teşvik etmektedir (Zhou \& Heekyoung, 2019). Bu bakımdan, platformun alışılagelmiş sosyal medya kullanım pratiklerine yeni perspektifler kazandırdığını söylemek mümkündür.

TikTok'un mevcut popüleritesini sağlaması noktasında çeşitlilik içeren bir pazarlama stratejisi oluşturması (ünlü kullanımı, reklam yatırımları, çevrimiçi ve çevrimdışı faaliyetleri birlikte yürütmesi, uluslararası bir rota çizmesi), güçlü bir yapay zeka teknolojisine sahip olması (kullanıcı eğilimlerini analiz edebilen bir algoritma mevcudiyeti, Dance Dancer teknolojisi adaptasyonu) ve kullanıc ihtiyaçlarını karşılaması (kullanıcının medya ihtiyaçlarına cevap vermesi ve kısa videolar sunarak bilgi karmaşasının önüne geçmesi) gibi parametrelerin etkin rol oynadığı saptanmıştır (Xu, Yan \& Zhang, 2019). Diğer yandan, TikTok'ta kullanıcıların hashtag kullanımı diğer sosyal ağlardaki hashtag kullanım amaçlarından farklılık göstermektedir. Platformda önemli bir role sahip olan hashtag'ler işlevsel bir organize etme rolüne sahiptir. Hashtag'ler genellikle challengelar, şakalar ve tekrar edilebilir formatlar gibi TikTok'tan başka hiçbir yerde popüler olmayan etkinliklerin organize edilmesinde kullanılmaktadır (Herrman, 2019). Bu etkinlikler platformda popüler olan bir şarkıya "playback" yapmak, belirli dans figürlerini hatasız gerçekleştirmek veya soru-cevap etkinliklerine katılmak gibi örnekler içermektedir. Bu durum diğer sosyal ağlardaki hashtag kullanımından farklılık göstermektedir. Çünkü diğer platformlarda hashtag kullanımı, kullanıcılara gerçek bir olay ve gündemi belirli bir akış içerisinde webosfer'de tartışma imkanı tanımaktadır. Fakat hashtag'ler TikTok'ta sadece TikTok kullanıcıları ekseninde gerçekleştirilebilen etkinliklerin organizasyonuna olanak tanımaktadır. Bu yönüyle hashtag kullanımı TikTok kullanıcılarının dikey bir eksende benlik sunumu pratiklerinde bulunmalarına ve benzer kullanıcıların içeriklerini inceleyerek kendi içeriklerini üretmek üzere fikir almalarına olanak tanımaktadır.

Zhou ve Heekyoung (2019), TikTok kullanıcılarını yaratıcı yeteneklerin öğrenimi ve paylaşımı noktasında üç kategori altında ele almışlardır. Kullanıcılar, içerik inceleyici grup, öğrenici-yaratıcı grup ve yaratıcı grup olarak kategorize edilmişlerdir. İçerik inceleyici grup çizim videoları üretmek, başka kullanıcıları takip etmek, videolara yorum yapmak veya onları beğenmek noktasında sınırlı miktarda sosyal aktiviteye dahil olmaktadır. Öğrenici-yaratıcı grup, öğrenme motivasyonları doğrultusunda videoları arşivlemekte ve ayrıca bu tipteki videolara yorum yaparak, beğenmektedir. Öğrenici-yaratıcı gruptaki kullanıcılar, nadiren kendi yaratıcı işlerini paylaşmaktadır. Yaratıcı grup ise, yeteneklerini yaratmak, dönüştürmek ve paylaşmak noktasında eylem ortaya koymaktadırlar. Bu gruptaki kullanıcılar diğer yaratıcıları da etkin şekilde takip etmekte ve işleriyle etkileşime geçmektedirler.

Bu kategorizasyon, yaratıcı yeteneklerin öğrenimi ve paylaşımı bağlamının ötesinde kalan alanlarda da TikTok kullanıcılarının platformdaki davranışlarını yorumlamak açısından önem taşımaktadır. Öyle ki, kimi kullanıcılar içerik inceleyici gruba benzer şekilde sadece yaratılan içerikleri tüketmekte, içerik üretimi ve yaratılmış içeriklerle etkileşime girme noktasında etkin olmayan bir rol üstlenmektedirler. Platformdaki kimi kullanıcılar ise, spesifik temalara ya da kullanıcılara ilgi duymakta, hashtag'ler aracılığı ile bu videolar izlemekte ve bu alanda içerik üreten kullanıcıları takip etmekte, sınırlı miktarda da içerik üretimi gerçekleştirmektedir. TikTok kullanıcılarından kimileri ise yaratıcı gruptaki kullanıcılara benzerlik göstermektedir. Bu gruba dahil olan kullanıcılar yüksek takipçi sayısına sahip, TikTok'ta ortaya çıkan akımlara katılan, platformun sunduğu teknik imkanlardan faydalanan, diğer kullanıcılar ve içeriklerle aktif şekilde etkileşime giren ve geniş kitlelere ulaşan içerikler üretmektedir.

\section{Amaç ve Yöntem}

Çalışma, TikTok kullanıcılarının, paylaştıkları video içerikleri aracılığıyla sergiledikleri benlik performanslarını analiz etmeyi amaçlamaktadır. Çalışmanın bir diğer amacı ise, kullanıcıların içerik üretim motivasyonları ve içerik üretimi sonucunda beklentilerinin keşfedilmesidir. Bu amaç doğrultusunda yanıtlanması hedeflenen araştırma sorularını ise, şöyle sıralamak mümkündür: 
AS1: TikTok kullanıcıları, video içeriği oluştururken sahne arkasında nasıl bir hazırlık yapmaktadırlar?

AS2: TikTok kullanıcıları, video paylaşımlarını hangi kriterleri gözeterek gerçekleştirmektedirler?

AS3: TikTok kullanıcıları, hedefledikleri dijital benlik sunumuna uygun olarak, hangi video içeriklerini paylaşmayı/paylaşmamayı tercih etmektedirler?

Çalışmanın amacına uygun olarak, yarı yapılandırılmış yüz yüze görüşme tekniğine dayanan betimsel bir alan araştırmasının gerçekleştirilmesi uygun görülmüştür. Söz konusu alan araştırmasında yer alacak katılımcıların belirlenmesinde ise, amaca yönelik örnekleme yönteminden yararlanılmıştır. Amaca yönelik örnekleme, ana kütle içinden bilgi istenen özelliği temsil edecek birimlerin tespit edilerek seçilmesi (Yazıcıoğlu \& Eroğlu, 2014: 82), çalışmanın amacına bağlı olarak, belirli ölçütleri karşılayan ve belirli ortak özelliklere sahip olan derinlemesine bilgi alınabilecek birimler üzerinden araştırma yapılmasına olanak tanıması bakımından uygun görülmüştür. Katılımcılar üzerinden toplanan verinin yeterli olduğu görüldüğünde ise, görüşmeler sonlandırılmıştır. Yüz yüze görüşme sürecinde DeMarris (2003) tarafından ortaya koyulan derinlemesine görüşme tasarım ve uygulama protokolünden faydalanılmıştır. Alan araştırmasında yer alacak katılımcıların belirlenmesinde ise, amaca uygun örnekleme yönteminden yararlanılmıştır. Bu doğrultuda çalışmaya dahil edilen katılımcılar; Zea veHeekyoung'un (2019) kategorizasyonuna göre, yaratıcı gruba dahil olan, yani hem aktif olarak içerik üreten hem de diğer kullanıcılarla sürekli etkileşim içerisinde olarak paylaşılan içeriği düzenli bir biçimde takip eden bireyler arasından seçilmiştir. Böylelikle, diğer kategorilerde yer alan kullanıcı profillerine nazaran, çalışmaya dahil edilen katılımcıların TikTok'ta bir sahne önü performansı sergileyen ve takipçileriyle etkileşim içerisinde olan kullanıcılar arasından seçilmiş olması hedeflenmiştir. Söz konusu çalışma grubunun demografik özelliklerine aşağıda yer verilmektedir:

\begin{tabular}{lccll}
\hline İsim & Cinsiyet & Yaş & Eğitim Durumu & Meslek \\
\hline M.A. & Erkek & 24 & Üniversite & Öğrenci \\
\hline S.M. & Erkek & 25 & Üniversite & Öğrenci \\
\hline B.V. & Erkek & 21 & Lise & İşsiz \\
\hline U.R. & Kadın & 17 & Lise & Öğrenci \\
\hline P.P. & Kadın & 17 & Lise & Öğrenci \\
\hline B.M. & Kadın & 18 & Lise & Öğrenci \\
\hline M.C.. & Erkek & 33 & Lise & Pastane işletmecisi \\
\hline C.Y. & Erkek & 26 & Üniversite & Tasarımcı \\
\hline R.Y. & Erkek & 25 & Üniversite & Öğrenci \\
\hline
\end{tabular}

Tablo 1: Çalışma grubunun demografik dağılımı.

Çalışma grubu belirlendikten sonra, araştırmanın teorik perspektifiyle ilişkili olarak yarı yapılandırılmış görüşme soruları ve formu oluşturularak, yüz yüze yarı yapılandırılmış görüşmeler gerçekleştirilmiştir. Görüşmelerdeki katılımcı ifadeleri, hem ses kaydının alınması hem de not tutulması aracılığıla kaydedilmiştir. Görüşmelerin her biri birebir olarak yapılmış, ortalama 35-50 dakika arasında sürmüş ve 28.03.2020 ile 17.04.2020 tarihleri arasında tamamlanmıştır. Sonrasında ise, katılımcı ifadeleri bilgisayar ortamına aktarılmış ve ulaşılan veriler analiz edilmiştir. Gerçekleştirilen yarı yapılandırılmış yüz yüze görüşmeler sonrasında toplanan verinin kategorizasyonu ve analizi sürecinde çalışmanın geçerlilik ve güvenilirliğinin sağlanabilmesi için sırasıyla şu adımlar izlenmiştir: çalışmada iç geçerliliği sağlamak üzere, verilerin toplanması ve analiz edilmesi sürecinde, aynı zamanda çalışmanın yazarı olan üç araştırmacı sürekli fikir alışverişinde bulunmuş, verilerin analizi kontrol edilmiş, literatür ve benzer araştırma analizleriyle karşılaştırılmıştır. Yapılan bu karşılaştırma aracılığıyla ulaşılan bulguların alanın literatürü ile uyumlu olduğu ve iç geçerliliğinin sağlanmasına katkı yaptığı görülmüştür. Dış geçerliliği sağlayabilmek için ise, araştırma metni içerisinde görüşme yapılan katılımcı ifadelerinden doğrudan alıntılar yapılmıştır. İç güvenilirliği sağlayabilmek amacıyla, katılımcılardan elde edilen 
veriler kaydedilmiş, gerçekleştirilen görüşmelerde ortak görüşme protokolü uygulanmış, veriler ortak başlıklarda toplanmış ve sonuçlar bir araya getirilmiştir. Ayrıca görüşme verileri analiz edilirken, çalışmanın teorik arka planından yararlanılması analizin iç güvenilirliğini sağlayan bir diğer faktör olmuştur. Araştırmanın dış güvenilirliğini sağlamak üzere ise, öncelikle araştırma sürecinin detaylı bir biçimde aktarılmasına dikkat edilmiştir. Ayrıca elde edilen bulgular, katılımcıların görüşlerinden alıntılar yapılarak desteklenmiş ve elde edilen verilerdeki farklı görüşler göz ardı edilmeden yansıtılmaya çalışılmıştır.

\section{Bulgular}

Katılımcılarla gerçekleştirilen yarı yapılandırılmış yüz yüze görüşmeler çerçevesinde, TikTok kullanıcılarına ilk olarak, paylaşım yapmadan önce -yani sahne arkasında- hangi kriterlere dikkat ettiklerine ve paylaşım yapacakları içeriği neye göre seçtiklerine ilişkin çeşitli sorular yöneltilmiştir. Buna göre, TikTok kullanıcılarının video paylaşırken öncelikle içeriğin güncel ve popüler olmasına dikkat ettiklerini söylemek mümkündür. TikTok kullanıcıları, video çekerken "popüler şarkılar ve gündemdeki meydan okumaları" (M.A., 24), "güncel ve trend olan içerikleri" (S.M., 25) tercih etmektedirler. Bununla birlikte, katılımcıların paylaşmayı seçtikleri bu popüler ve güncel içeriklerin, ileride kendilerini utandırmayacak bir nitelikte olmasına özen gösterdiklerini de eklemek gerekmektedir. Konuyla ilgili olarak, B.V. (21) ileride bir problemle karşılaşmamak için "içeriğin cinsellik ya da argo içerip içermediğini" özellikle kontrol ettiğinden, U.R. (17) daha sonra başka bir yerde karşılaştığında utanmayacağı bir içerik olmasına dikkat ettiğinden, P.P. (17), "cringe (utanma) olmayan" videoları tercih ettiğinden, utanılacak olanlardan ise, "özellikle sakındığından” bahsetmektedir. B.M. (18) ise, neden ileride kendisini utandırmayacak içerikler paylaşmayı seçtiğini şöyle aktarmaktadır: "Geleceğimde gördüğümde utanmayacağım bir içerik olmalı. Bu platformda yeniyim ve burada çok fazla saçma içerik var. Kullanıcıların bir kısmı kıro insanlar. Onlarla aynı level'da videolar yüklemek istemem." Bu çerçevede değerlendirildiğinde, katılımcıların video içeriği oluştururken, söz konusu içeriğin güncel ve popüler olmasına dikkat etmekle beraber, bu içeriklerin sonrasında kendi benlik sunumlarını olumsuz yönde etkilemeyecek olmasına da özen gösterdiklerini söylemek yanlış olmayacaktır. Bu kapsamda M.A. (24), popüler olan içerikler arasından hedeflediği benlik sunumuna uygun olanları nasıl seçtiğini şu sözlerle ifade etmektedir: "Popüler içeriklerden yapabileceklerimi çekerim. Yapamayacağım bir şey ise, onu denemem. Daha önceden yapmış olduğum ve iyi izlenimler aldığım videolara yakın içerikler çekmeyi de tercih ederim." Öte yandan, katılımcıların, diğer kullanıcılardan iyi izlenimler alma kriterlerinin de takipçileriyle girdikleri etkileşim oranı ve aldıkları beğeniye bağlı olduğunu belirtmek olanaklıdır. Bu çerçevede, M.Ç. (33) "etkileşim yaratacak ve çok beğeni alacak içerikleri", B.V. ise (21), "en çok sayıda takipçinin hoşuna gidecek içerikleri" oluşturmayı ve paylaşmayı tercih ettiğini vurgulamaktadır.

Katılımcılara, içerik oluşturma sürecindeki tercihlerinin yanı sıra, video çekimlerini gerçekleştirmeden önce sahne arkasında nasıl bir hazırlık süreci geçirdiklerine ilişkin de çeşitli sorular yöneltilmiştir. Buna göre, katılımcıların; kamera açısını ayarlamak, arka planı kontrol etmek, şarkı sözlerini ezberlemek ve deneme çekimi yapmak gibi birtakım hazırlıklar yaptıklarını söylemek mümkündür. Bunlar arasından, özellikle, şarkı sözlerini ezberlemenin ve deneme çekimi yapmanın videonun niteliğini arttıran unsurların başında gösterildiğini de eklemek gerekmektedir. Örneğin; S.M. (25) video çekimindeki hazırlık sürecini şöyle açıklamaktadır: "Öncesinde kamera açııını ayarlarım. Kamera açısından kötü gözüken eşyaları kaldırırım. Düzenleme yapmam gerekirse, yaparım. Deneme çekimi yapar, başarılı olana kadar kayıt altına almam. Tam olarak içime sindiğinde videoyu paylaşırım." Benzer biçimde, M.Ç. (33) ise, şunları aktarmaktadır: "Deneme çekimi yapıyorum, önce çocuklarla birkaç defa çalışıoruz. Sonra asıl videoyu çekiyoruz." Bununla birlikte, katılımcılar çekilen videolar öncesinde fonda yer alacak şarkının sözlerinin de ezberlenmesinin oldukça önemli olduğunun altını çizmektedir. Örneğin; P.P. (17) yayınladığı TikTok videolarında şarkı sözlerini ezberlemenin diğer kriterle nazaran çok daha önem taşıdığını şu sözlerle ifade etmektedir: "Şarkı sözlerini kesinlikle ezberlerim. Şarkı sözlerini ezberlemek diğer şeylerden çok daha önemli Tiktok'ta." Hazırlık süreci tamamlandıktan ve katılımcılar tarafından "en ideal olan" (B.M., 18) videonun çekimi yapıldıktan sonra ise, hazırlanan içeriğin bir düzenleme sürecine tabi tutulduğu da görülmektedir. Bu süreçte, kullanıcılar, efekt kullanılması, video renginin, sesinin ve süresinin düzenlenmesi ve çeşitli çıkartmaların eklenmesi gibi düzenlemeler gerçekleştirdiklerini belirtmektedirler. TikTok tarafından kendilerine sunulan video düzenleme araçlarından yararlandıktan sonra ise, videonun son halini yakın çevrelerine göndererek, onay almaktadırlar. Konuyla ilgili olarak, S.M. (25) çevresine danışarak videoyu 
yayınlamadan önce, son kez nasıl kontrol ettiğini şöyle açıklamaktadır: "Düzenlemeden sonra yakınlarıma gönderir, onay alırım. Eğer göremediğim bir hata olursa bu sayede görür ve düzeltirim."

Video içeriği oluşturulduktan ve düzenlenerek son halini aldıktan sonra, söz konusu içeriğin hangi zaman aralığında, hangi sıklıkta ve hangi başıkla paylaşılacağı da katılımcıların gözettikleri unsurlar arasında yer almaktadır. Buna göre, katılımcıların daha çok etkileşim alabilmek amacıyla, TikTok'un en çok kullanıldığı zaman aralığı olduğunu düşündükleri akşam saatlerinde (18:00-20:00 arası) video paylaşmaya özen gösterdiklerini söylemek mümkündür. Bununla birlikte, katılımcıların paylaştıkları içeriklerde belirli bir zaman aralığına dikkat etmedikleri, yayınlamaya uygun olduğunu düşündükleri video sayısına bağlı olarak içerik paylaşımında bulundukları da görülmektedir. Paylaşılan video yorumlarına ilişkin olarak ise, kullanıcılar, çok fazla metin eklemekten kaçınmakta, genellikle kısa video altı açıklamalarına yer vermekte, hashtag ya da emoji eklemektedirler. Bu çerçevede katılımcıların, video içerikleri paylaşırken çok fazla metin kullanmaktan özellikle kaçındıkları ve TikTok'un yapısı dolayısıyla videolara uzun metinler eklenmesine gerekli olmadığını düşündükleri söylenebilir. Bu bağlamda, B.M. (18) videolarına uzun metinler eklememe nedenini şöyle açıklamaktadır: "TikTok'ta kelimelerin pek bir anlamı yok. Yoruma da ihtiyaç olduğunu sanmıyorum." Diğer yandan, katılımcıların hashtag seçimlerinin videonun etkileşimini de arttırdığını ve videolara eklenen hashtag'lerin buna bağlı olarak seçildiğini de söylemek mümkündür. Örneğin; R.Y. (25), videolarının konusuyla ilgili hashtag'lerden ve video altı açıklamalarından yararlandığından, böylelikle yayınladığı videonun TikTok'un keşfet bölümüne düşmesini kolaylaştırdığından bahsetmektedir.

Çalışma amacına uygun olarak, katılımcılardan, TikTok videolarında sergiledikleri benlik performansları ve çevrimdışı ortamdaki benlik performansları arasında bir karşılaştırma yapmaları da istenmiştir. Bu çerçevede katılımcılara ilk olarak her iki ortamdaki benlik performanslarının birbirlerine hangi yönlerden benzediği ve farklııı gösterdiği sorulmuştur. Katılımcılar aslında her iki ortamda da aynı kişi olduklarını belirtmekle birlikte, TikTok videolarının konseptlerine bağlı olarak bir role büründüklerini ve üstlendikleri bu roller dolayısıyla çevrimdışı hayattaki benliklerinden tamamen farklılaştıklarını ifade etmişlerdir. Örneğin; benimsediği roller dolayısıyla çevrimdışı ortamdaki benlik performansından tamamen farklılaştığını vurgulayan R.Y. (25) şunları aktarmaktadır: "Genel olarak hiçbir yeri örtüşmüyor. Tamam komik bir insanım, doğal videolar çektiğim zaman kendim oluyorum. Ama playback'lerde otomatik olarak kendimizi sunmuyoruz, bize verilen kimliklere bürünüyoruz. Mesela Instagram'a attığım hikayelerde yüzde yüz benim. Ama TikTok'ta böyle bir imkan yok. Çünkü hikaye paylaşamıyorsunuz. Çektiğim videolar benim bir kimliğe bürünmemi sağlıyor. Çünkü bir adamın taklidini yapıyorsun, dans ediyorsun. Ben bunları yapan bir insan değilim normalde. Yani mecburen yeteneğini sergilemek zorundasın ya da o şey sende tatlı duruyor mu durmuyor mu insanlar bunu merak ediyor. Yani videoyu herkes çekebilir, herkes bir lafı tekrarlayabilir ama o tekrarladığın lafın senin üzerinde nasıl durduğu önemli." Benzer biçimde S.M. (25) ise, TikTok videolarında bir role büründüğünü ifade etmektedir: "Videolarda gerçek hayattaki gibi değilim, rol yapmaktayım." Bu bakımdan, katılımcıların çevrimdışı ve çevrimiçi ortamdaki benlik performanslarının büyük ölçüde farklılık gösterdiğini söylemek olanaklıdır. Katılımcıların büründükleri roller üzerinden ise, "sempatik, arkadaş canlısı, espritüel" (S.M., 25), "eğlenceli ve sempatik" (B.V., 21), "özgün ve estetik" (U.R., 17), "sempatik ve doğal" (P.P., 17), "komik bir adam olmak" (R.Y., 25), "göze güzel ve sempatik gelen" (B.M., 18) gibi çeşitli izlenimlere sahip olmak istedikleri ve video içeriklerini de bu yönde yapılandırdıkları görülmektedir. Örneğin; S.M. (25) özellikle sempatik davranmayı amaçladığından buna uygun içerikler üretmeye dikkat ettiğinden, B.V. (21) yayınladı̆̆ı videolar aracılığıyla takipçilerinin "psikolojilerini düzeltmek" istediğinden ve bu nedenle eğlenceli videolar çekmeyi tercih ettiğinden, P.P. (17) ise, ancak sempatik ve doğal olduğunda takipçi sayısını arttırabileceğini bildiğinden eğlenceli içerikler yayınlamaya odaklandığından bahsetmektedir. Dolayısıyla katılımcıların, TikTok videolarında çevrimdışı ortamdaki benlik performanslarının dışına çıkarak, büründükleri roller aracılığıyla, tıpkı Seidman'ın (2013: 402) da vurguladığı gibi, kendi alternatif benliklerini ifade edebilecekleri bir dijital sahneden yararlandıklarını ve bu sahnede hep olumlu yönlerini ve pozitif duygularını ön plana çıkarmaya odaklandıklarını söylemek yanlış olmayacaktır.

Bununla birlikte, katılımcıların kendilerine dair sunmak istedikleri bu alternatif benliklerini inşa ederken, bazı içerikleri özellikle paylaşmaktan kaçındıkları da görülmektedir. Söz konusu içeriklerin başında kişisel bilgileri ve kendilerine uygun olmadığını düşündükleri içerikler gelmektedir. TikTok üzerinden paylaştıkları videolarında 
çevrimdışı hayatlarına dair bilgi vermek istemediklerini aktaran katılımcı ifadelerinden bazılarını şöyle sıralamak mümkündür: "Yani mesela çalıştığım şirket bilinmesin isterim. Adım bilinebilir, Instagram hesabım bilinebilir, ama çalıştığım şirket, yaptığım iş çok da bilmesinler tavrındayım genel olarak." (C.Y., 26), "Özel hayatımın içeriklerimde yer almasını istemem. En çok buna dikkat ederim." (S.M., 25), "Videolarımda ailevi meselelere asla girmedim, bu konuda asla içerik paylaşmam" (B.V., 21). Kişisel bilgilerinin yanı sıra, kullanıcıların kendi yaratmak istedikleri izlenimlerine uygun olmadığını düşündükleri içerikleri de paylaşmaktan kaçındıkları görülmektedir. Örneğin; R.Y. (25) "kendi kişilik ve karakterine uygun olmayan içerikleri” paylaşmadığından bahsetmekte, B.M. (18) ise, "takipçi kasmak için" beğenmediği videoları asla yüklemediğini belirtmektedir. Bu bakımdan katılımcıların, hedefledikleri benlik sunumuna uygun olmadığını düşündükleri içerikleri paylaşmadıklarını ve daha fazla etkileşim alacak olmalarının da bu kararlarını etkilemediğini söylemek mümkündür. Ancak diğer yandan, kendi benlik performanslarına uygun olduğunu düşündükleri içerikleri arasından tercih yaparken alacakları etkileşim oranını göz önünde bulundurdukları görülmektedir. Örneğin; R.Y. (25) "Küfürlü içerikler, +18 kelimeler, alkol ve sigarayla ilgili dublajlar" gibi içeriklere yer vermekten kaçındığından, çünkü takipçilerinin küçük yaşta olmaları dolayısıyla bu tür içeriklerin onlara uygun olmadığından bahsetmekte, ancak takipçilerinden gelen önerileri de değerlendirdiğini ve aldığı etkileşime bağı olarak yayınlayıp yayınlamamaya karar verdiğini şöyle açıklamaktadır: "Bazen öneriler geliyor, bakıyorum, deniyorum, çekiyorum. Ama bazen verim alamadığımda o konuyu değil, başka bir konuyu çekiyorum. Yani neyden daha çok etkileşim alıyorsam, onu sürekli deniyorum." Dolayısıyla, kullanıcıların, takipçilerinden aldıkları etkileşim oranının yayınladıkları içerikler üzerinde belirleyici olduğu görülmektedir.

Ayrıca, katılımcılara paylaştıkları videoları sonrasında hedefledikleri benlik sunumlarına uyumsuz olduğunu düşünmeleri nedeniyle, silip silmedikleri de sorulmuştur. Verilen cevaplara bakıldığında ise, katılımcıların yeterince etkileşim almadığını düşündükleri videoları zaman içerisinde sildikleri görülmektedir. Örneğin; M.A. (24) "önce bir hevesle çekip, sonra basit bir içerik olduğuna karar verdiği", B.V. (21) "takipçiler tarafından fazla görüntülenmeyen ve beğenilmeyen", B.M. (18) "etkileşim almayan" videolarını sildiğinden bahsetmektedir. Bu bakımdan, katılımcıların TikTok hesaplarını hedefledikleri dijital benlik sunumlarına uygun olarak, sürekli güncellediklerini ve benlik performanslarını olumsuz etkilediğine inandıkları içerikleri de kaldırdıklarını belirtmek olanaklıdır.. Dolayısıyla dijital benlik performansının, bireyin paylaştığı ve kendisi hakkında paylaşılanların bir bütünü olduğu düşünüldüğünde, takipçilerinden alınan etkileşim oranının da, bireyin dijital benliğini inşa ederek, karşı tarafa sunabilmesi için önemli bir araca (Chen, 2016; Kurtin vd., 2018; Rasmussen, 2018) dönüştüğünü söylemek yanlış olmayacaktır.

Buna ek olarak, çalışma süresi içerisinde TikTok'taki bazı video içeriklerinin, birden fazla kişiyle çekilmesini gerekli kıldığı ile karşılaşılmıştır. Bu nedenle katılımcılara, videolarında yer verdikleri diğer kişileri seçerken nelere dikkat ettikleri de sorulmuş, böylelikle katılımcıların videolarında yer alan kişileri seçerken kendi benlik sunumlarını gözetip gözetmediklerinin ortaya koyulması hedeflenmiştir. Buna göre, katılımcıların videolarında yer verdikleri bireyleri, kendi benlik performanslarına katkı sağlayacağını düşündükleri kişiler arasından seçtiklerini ve videolarında bu kişilere çeşitli roller dağıttıklarını söylemek mümkündür. Konuyla ilgili olarak, M.Ç. (33) seçtiği kişilerin öncelikle "oyunculuğuna ve yeteneğine" baktığından, B.V. (21) videolarda kendisine eşlik edecek kişileri özel olarak seçtiğinden ve "istediği imajı oluşturacak kişilere" yer verdiğinden bahsetmektedir. R.Y. (25) ise, videolarında yer alan kişileri, kendi benlik performansını destekleyecek karakterlere nasıl büründürdüğünü şöyle açıklamaktadır: "Benim videom olduğu için gelen kişiyi istediğim karaktere, kişiliğe sokabiliyorum. (...) Yönetmenler biz olduğumuz için istediğimiz gibi o insanı o şekle sokabiliyoruz." (R.Y., 25)

\section{SONUÇ}

Dijital iletişim ortamlarının kullanımının yaygınlaşması, bireylerin benlik performanslarını sergilemelerine olanak sağlayan sahneleri de çeşitlendirmiş, günümüzde bireyler, hedefledikleri benlik sunumlarını takipçilerine/arkadaşlarına sergileyebilme ve dijital benliklerini inşa edebilme imkanını elde etmişlerdir. Bu bağlamda, özellikle video paylaşım platformları hem kullanıcılarını performanslarını sergileyebilecekleri izleyicilerle buluşturması hem de birey ile izleyici arasındaki etkileşimi sağlayacak bir altyapı sunması bakımından ön plana çıkmaktadır. Söz konusu platformlardan biri olan TikTok ise, bireye benlik performansını 
gerçekleştirebilmesi için videolarını düzenleyerek, ilgi çekici kılabilme ve diğer kullanıcılarla etkileşime girebilme imkanı sağlaması açısından önem taşımaktadır. Bu odak noktasından yola çıkan çalışma çerçevesinde, son yıllarda yüksek kullanıcı oranına sahip olan TikTok'ta bireyler tarafından gerçekleştirilen benlik performanslarının analiz edilmesi ve kullanıcıların bu süreçteki içerik üretim motivasyonları ile içerik üretimi sonucundaki beklentilerinin belirlenmesi hedeflenmiştir.

Ulaşılan araştırma bulgularına göre, kullanıcılar paylaşacakları video içeriklerini kendileri için olumsuz bir benlik sunumuna neden olmayacak, TikTok'taki güncel ve popüler konular arasından seçmektedir. Ayrıca kullanıcıların içeriğini oluşturdukları bu videoların, yayınlanma aşamasına gelene kadar, sahne arkasında bir düzenleme sürecinden geçtiği de görülmektedir. Bu süreçte kullanıcılar; kamera açısını ayarlamak, arka planı kontrol etmek, şarkı sözlerini ezberlemek ve deneme çekimi gibi çeşitli düzenlemeler yapmaktadır. Paylaşılacak içeriğin niteliğini arttıracağının düşünüldüğü en önemli düzenlemeler arasında ise, şarkı sözlerinin ezberlenmesi ve deneme çekiminin yapılması yer almaktadır.

Videonun hazırlık süreci tamamlandıktan sonra, kullanıcılar, benlik sunumları için en ideal olan içeriğe, efekt kullanılması, video renginin, sesinin ve süresinin düzenlenmesi ve çeşitli çıkartmaların eklenmesi gibi düzenleme araçları vasıtasıyla son halini vermektedirler. Bu çerçevede değerlendirildiğinde, video içeriği yayınlanmadan önce, kullanıcıların TikTok'un kendilerine sunduğu yüksek kontrol imkanından yararlandıklarını ve bu kontrol sürecinde sahneye sunacakları içeriğin her parçası üzerinde düşündüklerini söylemek mümkündür. Hatta öyle ki, kullanıcıların hazırladıkları videonun son halini yakın çevrelerine göndererek, içeriğin uygunluğuna dair onay aldıkları bile görülmektedir. Bu bakımdan ulaşılan araştırma bulgularının, Yau ve Reich (2018) tarafından gerçekleştirilen araştırma sonuçlarıyla tutarlılık gösterdiğini, bireylerin sosyal ağlarda paylaşım yapmadan önce çevresindekilerin görüşüne başvurarak, üzerinde fikir birliğine varılan en fazla beğenilme potansiyeline sahip içeriği paylaşmayı tercih ettiklerini söylemek yanlış olmayacaktır. Yani kullanıcıların sahne arkasında kurguladıkları benlik sunumlarını kolektif bir değerlendirme sürecine tabi tutarak, çevrelerinden de söz konusu içeriğin uygunluğuna dair onay almayı beklediklerini görülmektedir. Üzerinde fikir birliğine varılan içerik ise, TikTok'un en çok kullanıldığı zaman aralığı olduğu düşünülen akşam saatlerinde paylaşılmaktadır. Ayrıca kullanıcılar, paylaştıkları video içeriklerinde TikTok'un yapısına uygun olduğunu ve daha fazla etkileşim alacağını düşünmeleri nedeniyle, çok fazla metin eklemekten kaçınmakta, genellikle kısa video altı açıklamalarına yer vererek, hashtag ya da emoji eklemektedirler.

Katılımcıların sahne arkasında hazırlayarak, sahne önüne taşıdıkları içeriklere dair düşünceleri incelendiğinde ise, TikTok videolarının konseptlerine bağlı olarak bir role büründüklerini ve üstlendikleri bu roller dolayısıyla çevrimdışı hayattaki benliklerinden tamamen farklılaştıklarını ifade ettikleri görülmektedir. Benimsenen bu roller arasında ise, takipçiye sempatik ve eğlenceli gelecek görünümler ön plana çıkmakta ve kullanıcıların video içeriklerini bu yönde şekillendirdikleri ile karşılaşılmaktadır. Söz konusu izlenimin tercih edilmesinin nedeni ise, kullanıcıların bu izlenimlere sahip olduklarında takipçileri nezdinde daha fazla etkileşim alacaklarını düşünmeleridir. Ek olarak, kullanıcılar sahne önüne taşımak istedikleri benlik sunumlarını sergileyebilmek için bazı içerikleri de paylaşmaktan özellikle kaçınmaktadır. Bu içeriklerin başında, kullanıcıların kişisel bilgileri ve kendi benlik sunumlarına uygun olmadığını düşündükleri içerikler gelmektedir. Ayrıca kullanıcıların daha fazla etkileşim alma ihtimalleri de, benlik sunumlarına uygun olmadığını düşündükleri içerikleri paylaşmama kararlarını etkilememektedir. Ancak diğer yandan, etkileşim oranı kullanıcının kendi benlik sunumuna uygun olduğunu düşündüğü içerikler arasından seçim yaparken göz önünde bulundurduğu en önemli kriter olarak karşımıza çıkmaktadır. Bu çerçevede değerlendirildiğinde, bireylerin yaratmak istedikleri izlenimlerine uygun olduğunu düşündükleri içeriği aldıkları etkileşim oranına bağlı olarak şekillendirdiğini ve sahne önünde hangi rolleri benimseyeceklerini de yine etkileşim alma potansiyeline bağlı olarak belirlediklerini söylemek mümkündür. Ek olarak, kullanıcıların videolarında yer alacak kişileri de kendi benlik performanslarına katkı sağlayacağına inandıkları bireyler arasından seçtikleri ve tıpkı kendi benimsedikleri roller gibi onlara da çeşitli roller dağıttıkları görülmektedir. Bununla birlikte, kullanıcıların yeterince etkileşim almadığını düşündükleri videoları zaman içerisinde silmektedir. Bu bakımdan, bireylerin TikTok hesaplarını hedefledikleri dijital benlik sunumlarına uygun olarak, sürekli güncelledikleri ve benlik performanslarını olumsuz etkilediğine inandıkları içerikleri de kaldırdıkları söylenebilir. 
Sonuç olarak, kullanıcıların hedeflediği benlik sunumlarını gerçekleştirerek, takipçileriyle bir anlaşmaya vardıkları sonucuna ulaşabilmeleri için elde etmeye çalıştıkları en önemli verinin aldıkları etkileşim oranı (beğeni ve yorum sayısı) olduğunu söylemek mümkündür. Ayrıca kullanıcıların alacakları bu etkileşimin hem seçtikleri içerik üzerinde belirleyici olduğu hem de sahne arkasındaki hazırlık sürecini şekillendirdiği görülmektedir. Bununla birlikte, kullanıcılar, sahne önünde sundukları video içeriklerinde bir role büründüklerini söylemektedirler. Kullanıcıların, büründükleri bu rolün başarısının da yine takipçilerinden aldıkları etkileşim oranıyla ölçümlediklerini ve etkileşimin sonraki rollerin tercihinde (challenge'lar, videoda yer alacak kişi sayısı, videoda kimlerin yer alacağı vb.) de önemli bir belirleyici olduğunu ifade etmek olanaklıdır. Dolayısıyla, TikTok kullanıcılarının hem sosyal medyanın kimlik keşfi ve inşasına olanak tanıyan (Yau \& Reich, 2018: 196) yapısal özelliğinden hem de TikTok'un sunduğu olanaklardan yararlanarak, kendilerine dair olumlu yönleri ortaya çıkaran içerikleri daha çok sergilemeyi hedeflediklerini ve bu içerikler üzerinden aldıkları etkileşim oranını bağlı olarak içerik üretim pratiklerini yapılandırdıklarını söylemek mümkündür.

\section{KAYNAKÇA}

Bilgin, N. (2016). Sosyal Psikoloji Sözlüğü, Kavramlar, Yaklaşımlar. İstanbul: Bağlam Yayıncılık.

Bortree, D.S. (2005). "Presentation of Self on the Web: An Ethnographic Study of Teenage Girls' Web Logs." Education, Communication, \& Information, 5(1): 25-39.

Bryant, E.M. \& Marmo, J. (2012). "The Rules of Facebook Friendship: A Two-stage Examination of Interaction Rules in Close, Casual, and Acquaintance Friendships". Journal of Social and Personal Relationships, 29(8): 1013-1035.

Bump, P. (2020). 26 TikTok Status to Know in 2020. https://blog.hubspot.com/marketing/tiktok-stats adresinden alındı.

Caplan, S.E. (2005). "A Social Skill Account of Problematic Internet Use." Journal of Communication, 55(4): 721736.

Chen, C. (2016). "Forming Digital Self and Parasocial Relationship on Youtube”. Journal of Consumer Culture, 16(1): 232-254.

Chen, C.L. (2013). "Digital Self and Parasocial Interaction on Youtube". In. E-European Advances in Consumer Research Volume 10, (Eds. Gert Cornelissen, Elena Reutskaja \& Ana Valenzuela), Duluth, MN: Association for Consumer Research, p. 126-127.

Chou, H.G. \& Edge, N. (2012). "They are Happier and Having Better Lives than I am": The Impact of Using Facebook on Perceptions of Others' Lives". Cyberpsychology, Behavior and Social Networking, 15(2): 117-121.

Davis, K. (2012). “Friendship 2.0: Adolescents' Experiences of Belonging and Self-Discourse Online”. Journal of Adolescence, 35(6): 1527-1536.

DeMarrais, K. (2003). Qualitative interview studies: Learning through experience. In Foundations for Research: Methods of Inquiry in Education and the Social Sciences.(Eds. S.D. DeMarrais \& K. Lapan), Mahwah: Lawrence Erlbaum Associates.

Fardouly, J., Magson, N.R., Rapee, R.M.,Oar, E.L. \& Johnco, C.J. (2018). The Use of Social Media by Australian Preadolescents and Its Links with Mental Health. Journal of Clinical Psychology, https://doi.org/10.1002/jclp.22936

Geurin-Eagleman, A. \& Burch, L.M. (2016). "Communicating via Photographs: A Gendered Analysis of Olympic Athletes' Visual Self-Presentation on Instagram". Sport Management Review, 19(2): 133-145.

Gibbs, J.L., Ellison, N.B. \& Heino, R.D. (2006). "Self-presentation in Online Personals: The Role of Anticipated Future Interaction, Self-disclosure, and Perceived Success in Internet Dating". Communication Research, 33(2): 152-177.

Goffman, E. (2016). Günlük Yaşamda Benliğin Sunumu. İstanbul: Metis Yayıncılık.

Herrman, J. (2019). Journal of Advanced Management Science. https://www.nytimes.com/2019/03/10/style/what-is-tik-tok.html adresinden alındı.

Hogan, B. (2010). "The Presentation of the Self in the Age of Social Media: Distinguishing Performances and Exhibitions Online". Bulletin of Science, Technology and Society, 30(6): 377-386. 
Jackson, C.A. \& Luchner, A.F. (2018)."Self-presentation Mediates the Relationship Between Self-criticism and Emotional Response to Instagram Feedback". Personality and Individual Differences, 133: 1-6.

Jensen S. H. \& Gilly, M.C. (2003). "We Are What We Post? Self-presentation in Personal Web Space." Journal of Consumer Research, 30(3): 385-404.

Jung, H.,\& Zhou, Q. (2019). Learning and Sharing Creative Skills with Short Videos: A Case Study of User Behavior in TikTok and Bilibili. In International Association of Societies of Design Research(IASDR). United Kingdom.

Kağıtçıbaşı, Ç. (2006). Yeni insan ve insanlar. İstanbul: Evrim Yayınevi.Kihlstrom, J.F. \& Cantor, N. (1984). "Mental Representation of Self". Advances in Experimental Social Psychology, 17: 1-47.

Kim, H. \& Papacharissi, Z. (2003). "Cross-cultural Differences in Online Self-Presentation: A Content Analysis of Personal Korean and US Home Pages." Asian Journal of Communication, 13(1): 100-119.

Ko, H. \& Wu, W. (2017). "Exploring the Determinants of Viewers' Loyalty toward Beauty Youtubers: A Parasocial Interaction Perspective". In Proceedings of the 2017 International Conference on Education and Multimedia Technology.

Kurtin, K.S., O’Brien, N., Roy, D. \&Dan, L. (2018). "The Development of Parasocial Relationships on Youtube". The Journal of Social Media and Society, 7(1): 233-252.

Leary, M.R. \& Kowalski, R.M. (1990). “Impression Management: A Litreature Review and Two Component Model." Psychological Bulletin, 107(1): 34-47.

Lebel, K. \& Danylchuk, K. (2012). "How Tweet It Is: A Gendered Analysis of Professional Tennis Players' Selfpresentation on Twitter". International Journal of Sport Communication, 5(4): 461-480.

Lebel, K. \& Danylchuk, K. (2014). "An Audience Interpretation of Professional Athlete Self-Presentation on Twitter". Journal of Applied Sport Management, 6(2): 16-36.

Litt, E. (2012). “Knock, Knock. Who's There? The Imagined Audience”.Journal of Broadcasting and Electronic Media, 56(3): 330-345.

Lu, X.,\& Lu, Z. (2019). Fifteen Seconds of Fame: A Qualitative Study of Douyin, A Short Video Sharing Mobile Application in China. In Social Computing and Social Media. Design, Human Behavior and Analytics, (Ed.G. Meiselwitz), Cham: Springer International Publishing. p. 233-244.

Marvick, A.E. \& boyd, D. (2011). “I Tweet Honestly, I Tweet Passionately: Twitter Users, Context Collapse, and the Imagined Audience". New Media and Society, 13(1): 114-133.

Mehdizadeh, S. (2010). "Self-presentation 2.0: Narcissism and Self-esteem on Facebook". Cyberpsychology, Behavior, and Social Networking, 13(4): 357-364.

Pace, S. (2008). "Youtube: An Opportunity for Consumer Narrative Analysis?". Qualitative Market Research: An International Journal, 11(2): 213-226.

Papacharissi, Z. (2002). "The Presentation of Self in Virtual Life: Characteristics of Personal Home Pages." Journalism \& Mass Communication Quarterly, 79(3): 643-660.

Rasmuseen, L. (2018). "Parasocial Interaction in the Digital Age: An Examination of Relationship Building and the Effectiveness of Youtube Celebrities". The Journal of Social Media in Society, 7(1): 280-294

Rosenberg, J. \& Egbert, N. (2011). “Online Impression Managemet: Personality Traits and Concerns for Secondary Goals as Predictors of Self-presentation Tactics on Facebook". Journal of Computer-Mediated Communication, 17(1): 1-18.

Salinas, S. (2018). TikTok is the Latest App to Skyrocket in Popularity. Here's Why It Might Have Staying Power. https://www.cnbc.com/2018/11/22/what-is-tiktok.htmladresinden alındı.

Seidman, G. (2013). "Self-presentation and Belonging on Facebook: How Personality Influences Social Media Use and Motivations". Personality and Individual Differences, 54(3): 402-407.

Shao, T., Wang, R., \& Hao, J.-X. (2019). Visual Destination Images in User-generated Short Videos: An Exploratory Study on Douyin. In 2019 16th International Conference on Service Systems and Service Management (ICSSSM).

Smith, L.R. \& Sanderson, J. (2015). "I'm Going to Instagram it! An Analysis of Athlete Self-presentation on Instagram". Journal of Broadcasting \& Electronic Media, 59(2): 342-358.

Timisi, N. (2005). "Sanallığın Gerçekliği: İnternetin Kimlik ve Topluluk Alanına Girişi". Internet, Toplum, Kültür. (Ed. M. Binark \& B. Kılıçbay), Ankara: Epos Yayınları, 89-105. 
Van Der Heide, B., Angelo, J.D. \& Schumaker, E.M. (2012). "The Effects of Verbal Versus Photographic SelfPresentation on Impression Formation in Facebook". Journal of Communication, 62(1): 98-116.

Vogel, E.A. \& Rose, J.P. (2016). "Self-reflection and Interpersonal Connection: Making the Most of Selfpresentation on Social Media". Translational Issues in Psychological Science, 2(3): 294-302.

Xu, L., Yan, X.\& Zhang, Z. (2019). Research on the Causes of the "Tik Tok" App Becoming Popular and the Existing Problems. Journal of Advanced Management Science, 7(2): 59-63.

Yau, J.C. \& Reich, S.M. (2018). “"It's Just a Lot of Work”: Adolescents' Self-Presentation Norms and Practices and Instagram". Journal of Research on Adolescence, 29(1): 196-209.

Yazıcıoğlu, A. \& Eroğlu, C. (2014). SPSS Uygulamalı Bilimsel Araştırma Yöntemleri. Ankara: Detay Yayıncılık.

Zhang, X., Wu, Y.\& Liu, S. (2019). Exploring Short-form Video Application Addiction: Socio-technical and Attachment Perspectives. Telematics and Informatics, 42: 101-243.

Zhao, S., Grasmuck, S. \& Martin, J. (2008). "Identity Construction on Facebook: Digital Empowerment in Anchored Relationships". Computers in Human Behavior, 24(5): 1816-1936. 